\title{
The crucial role of gibberellic acid on germination of drought-resistant upland rice
}

\author{
J.-Z. LI, M.-Q. LI, Y.-C. HAN, H.-Z. SUN, Y.-X. DU, and Q.-Z. ZHAO* \\ Henan Key Laboratory of Rice Biology, Henan Agricultural University, Zhengzhou 450002, P.R. China
}

\begin{abstract}
Drought is one of the main factors restricting seed germination. In order to reveal the physiological and molecular mechanisms of improved germination ability in upland rice under drought stress, we investigated the seed germination characteristics and the expression of genes related to gibberellic acid $\left(\mathrm{GA}_{3}\right), \alpha$-amylase, and expansin of upland rice cultivar IRAT109 and lowland rice cultivar Yuefu under drought stress induced by $15 \%(\mathrm{~m} / \mathrm{v})$ polyethylene glycol (PEG) and $\mathrm{GA}_{3}$ application. Seed germination decreased in upland rice and lowland rice under PEG-induced stress; upland rice was less affected than lowland rice. The germination vigour, root length, and shoot length were significantly higher in upland rice than in lowland rice under PEG stress. The $\mathrm{GA}_{3} /$ abscisic acid ratio, $\alpha$-amylase activity, and soluble sugar content in the germinated seeds were higher in upland rice. An RNA sequencing analysis revealed that 14 genes related to gibberellins, $\alpha$-amylase, and expansin had a significantly higher expression in upland rice than in lowland rice. On the other hand, application of $\mathrm{GA}_{3}$ significantly increased the germination vigour, shoot length, root length, $\alpha$-amylase activity, and soluble sugar content in upland rice. It also induced higher expressions of $\boldsymbol{\alpha}$-amylase and expansin related genes in upland rice. The results indicate that $\mathrm{GA}_{3}$ plays an important role in promoting seed germination in upland rice under drought stress by increasing the expressions of $\alpha$-amylase and expansin genes.
\end{abstract}

Additional key words: abscisic acid, $\alpha$-amylase, expansin, Oryza sativa, polyethylne glycol, RNA sequencing.

\section{Introduction}

Dry direct-seeded rice (DSR) is a popular and promising method for planting rice, due to less labour, less water, and possibility of mechanized planting (Mahender et al. 2015). Arapid and uniform seed germination is essential for DSR (Farooq et al. 2006, Liu et al. 2014). Seed germination is an important stage including seed imbibition, enzyme activation, cell division and enlargement, and development of embryo axis through the seed coat (Bewley 1997). Water absorbed in the first step of seed germination activates enzymes (Miransari and Smith 2014) and DSR is vulnerable to germination failure due to insufficient water supply. So, cultivars used for DSR should have a high germination ability, high seedling vigour, and fast root growth (Hu and Xiong 2014, Mahender et al. 2015, Lee et al. 2017).

Among the plant hormones, gibberellins (GAs) promote seed germination whereas abscisic acid (ABA) inhibits it (Rajjou et al. 2012, Zhao et al. 2014). The antagonism between GAs and ABA plays an important role in controling seed germination, and they interact also with environmental factors in mediating seed germination (Zhao et al. 2014, Shu et al. 2016). During seed germination, active GAs are synthesized in the embryo and transported to the aleurone layer inducing the expression of $\alpha$-amylase gene and subsequently its synthesis. The biosynthesis of GAs is catalyzed by ent-copalyl diphosphate synthase, ent-kaurene synthase, ent-kaurene oxidase, ent-kaurene acid oxidase, GA 13-oxidase (GA13ox), GA 20-oxidase (GA20ox), and GA 3-oxidase (GA3ox) (Liu et al. 2018).

Upland rice has a higher germination ability under drought stress than lowland rice. The GAs promotes seed germination by releasing seed dormancy and by stimulating the synthesis and production of the hydrolases involved in the breaking of seed storage reserves. However, the mechanisms responsible for higher germination in upland rice under drought stress are not known. Whether GAs perform the same function during seed germination in upland rice or lowland rice under drought stress is also

Submitted 23 July 2018, last revision 4 February 2019, accepted 6 February 2019.

Abbreviations: ABA - abscisic acid; DEGs - differently expressed genes; DSR - dry direct-seeded rice; GA - gibberellins; GA 3 gibberellic acid; PEG - polyethylene glycol; RNA-seq - RNA sequencing analysis.

Acknowledgments: This research was supported by the National Key Research and Development Program of China (2017YFD0100505), the National Nature Science Foundation of China (31671667), and the Scientific and Technological Innovative Talents Supporting Project in Universities of Henan Province (16HASTIT016).

*Corresponding authors; e-mails: lijzh78@hotmail.com; qzzhaoh@126.com 
not clear. Therefore, we investigated the seed germination characteristics and performed a comparative transcriptional expression analysis during seed germination under drought stress and gibberellic acid $\left(\mathrm{GA}_{3}\right)$ application using upland rice cultivar IRAT109 and lowland rice cultivar Yuefu.

\section{Materials and methods}

Plants and treatments: Rice (Oryza sativa L.) cvs. IRAT109, an upland tropical japonica cultivar, and Yuefu, a lowland temperate japonica cultivar, were used in this study. Seeds were surface sterilized in $10 \%(\mathrm{v} / \mathrm{v}) \mathrm{H}_{2} \mathrm{O}_{2}$ for $10 \mathrm{~min}$ and rinsed six times with distilled water. Sterilized seeds were soaked in distilled water at $28{ }^{\circ} \mathrm{C}$ for $24 \mathrm{~h}$. Then the seeds were placed in sterile Petri dishes with moistened filter paper and grown in a growth chamber for $1,2,3,4$, and $5 \mathrm{~d}$ under three different treatments, water, $15 \%(\mathrm{~m} / \mathrm{v})$ polyethylene glycol 6000 (PEG), and PEG plus $0.1 \mu \mathrm{M} \mathrm{GA}_{3}(\mathrm{PEG}+\mathrm{GA})$. A growth chamber was set at a 8 -h photoperiod, day/night temperatures of $28 / 25{ }^{\circ} \mathrm{C}$, a $75 \%$ relative humidity, and an irradiance of $300 \mu \mathrm{mol} \mathrm{m} \mathrm{m}^{-2} \mathrm{~s}^{-1}$. The water potential was $-0.32 \mathrm{MPa}$ under $15 \%$ PEG treatment. Each treatment had three replicates with 100 seeds per replicate.

The germination rate after $3 \mathrm{~d}$ of treatment is considered as germination vigour. Root length and shoot length were measured after 3, 4, and $5 \mathrm{~d}$ of treatment.

Quantification of endogenous phytohormones: The content of $\mathrm{GA}_{3}$ and $\mathrm{ABA}$ in the seeds were determined using enzyme-linked immunosorbent assay kits (China Agricultural University, China) (Yang et al. 2001). Germinating seeds after one day of treatment were incubated in $80 \%(\mathrm{v} / \mathrm{v})$ methanol at $4{ }^{\circ} \mathrm{C}$ for $48 \mathrm{~h}$. The extracts were collected after centrifugation at $10000 \mathrm{~g}$ and $4{ }^{\circ} \mathrm{C}$ for $15 \mathrm{~min}$ and filtered through a Sep-Pak C18 cartridge (Waters, Milford, MA, USA), dried by pure $\mathrm{N}_{2}$ at $20^{\circ} \mathrm{C}$, and stored at $-40{ }^{\circ} \mathrm{C}$. The residues were dissolved in phosphate buffered saline ( $\mathrm{pH} 7.5)$ containing $0.1 \%(\mathrm{v} / \mathrm{v})$ Tween 20 and $0.1 \%(\mathrm{~m} / \mathrm{v})$ gelatine to quantify $\mathrm{GA}_{3}$ and ABA content.

$\alpha$-Amylase activity and soluble sugar content: The germinating seeds were collected to determine $\alpha$-amylase activity and total soluble sugar content. The $\alpha$-amylase activity was determined using an Amylase Assay kit purchased from Suzhou Komin Biotechnology Company (Suzhou, China), following manufacturer's instructions. Seeds were ground and mixed $(1 \mathrm{~g})$ with $10 \mathrm{~cm}^{3}$ of phosphate buffer ( $\mathrm{pH} 7.0)$ at $4{ }^{\circ} \mathrm{C}$ for $24 \mathrm{~h}$. Enzyme activity of the supernatant was measured by 3,5-dinitrosalicylic acid (DNS) method (Bernfeld 1955, Basra et al. 2005). Starch hydrolase catalyzes the hydrolysis of starch into reducing sugars; DNS produces a brown-red compound on reacting with reducing sugars. $\beta$-Amylase was inactivated at 70 ${ }^{\circ} \mathrm{C}$ for $15 \mathrm{~min}$. The activity of $\alpha$-amylase was measured at $540 \mathrm{~nm}$ using a spectrophotometer $(U V-3200 P C$, $M A P A D A$, Shanghai, China). For soluble sugars, ground seed samples $(1 \mathrm{~g})$ were mixed with $10 \mathrm{~cm}^{3}$ of distilled water at $25{ }^{\circ} \mathrm{C}$ for $24 \mathrm{~h}$. The extract was filtered through filter paper. The final volume was adjusted to $10 \mathrm{~cm}^{3}$ with distilled water. The soluble sugar content was determined by phenol sulfuric method (Dubois et al. 1956, Lee and Kim 2000).

Total RNA isolation, cDNA library construction, and sequencing: Total RNA was isolated from seeds treated with $15 \%(\mathrm{~m} / \mathrm{v})$ PEG and distilled water for one day. Total RNA was extracted using a TranZol RNA extraction kit (TransGen Biotech, Beijing, China) and three biological replicates were used. The cDNA libraries were prepared individually for each sample by performing a series of procedures, including mRNA enrichment by oligo (dT), removal of rRNA and RNA fragments, cDNA synthesis using random hexamer primers, size selection, and PCR amplification. The cDNA libraries were prepared using an mRNA-Seq sample preparation kit (Illumina, San Diego, USA). The Illumina Hiseq ${ }^{\mathrm{TM}} 2000$ platform was used to sequence the libraries, and paired-end reads were generated. Illumina sequencing was designed and experimented at Biomarker Technologies Corporation (Beijing, China).

Analysis of RNA-seq data: Raw data were filtered to remove low-quality reads and adaptor contamination by using in-house Perl scripts. The clean reads were mapped to the rice cv. Nipponbare reference genome with TopHat. The sequence alignment files generated by TopHat were provided as input to Cufflinks (Trapnell et al.2010) and assembled the alignments into transfrags. Cufflinks statistical model probabilistically assigns reads to the assembled isoforms. Unique reads were aligned by $B L A S T X$ (e-value $\left.\leq 10^{-5}\right)$ to a series of databases including NCBI non-redundant (Nr), Swiss-Prot, Kyoto encyclopedia of genes and genomes $(K E G G)$, and gene ontology $(G O)$. Differential expression analysis of genes between two cultivars was performed by using the DEGseq (2010) $R$ package (Anders and Huber 2010).Differentially expressed genes (DEGs) were ranked according to their size and normalized FPKM (fragments per kilo base of exon per million reads). The DEGs of different samples were analyzed according to the $\log _{2}$ fold changes of FPKM. The significant threshold was set at $P<0.05$ and $\log _{2}$ (ratio) $\geq 1$.

Real-time quantitative PCR: Approximately $1 \mu \mathrm{g}$ of total RNA was reverse-transcribed using the GoScript ${ }^{\mathrm{TM}}$ reverse transcription system (Promega, Madison, USA) according to the manufacturer's instructions to obtain cDNA. The amount of transcripts of each gene was measured in a total volume of $20 \mathrm{~mm}^{3}$ containing $0.8 \mathrm{~mm}^{3}$ of forward and reverse primers, $5 \mathrm{~mm}^{3}$ of the reversetranscribed product, $4.2 \mathrm{~mm}^{3}$ of nuclease-free water, and $10 \mathrm{~mm} 3$ of GoTaq ${ }^{\circledR}$ qPCR Master Mix (Promega, Madison, USA) on an Applied CFX96 real-time PCR system (BioRad, Hercules, USA) according to the manufacturer's instructions. The cycling conditions were $95^{\circ} \mathrm{C}$ for $10 \mathrm{~min}$ by 39 cycles of amplification $\left(95^{\circ} \mathrm{C}\right.$ for $15 \mathrm{~s}$ and $60{ }^{\circ} \mathrm{C}$ for $1 \mathrm{~min})$. The transcription was normalized using rice 
ACTIN (LOC Os03g50885) as an internal reference gene. For each sample, three biological replicates and three technical replicates were used. The relative expressions were determined using the $2^{-\triangle \Delta \mathrm{CT}}$ method. The primers are given in Table 1 Suppl.

Statistical analyses: All analyses were performed using SPSS Statistics 18.0 (SPSS, Chicago, IL, USA). Data are averages of biological replicates represented as means \pm standard errors. Means were compared with the least significant difference test (LSD test) at $\alpha=0.05$ or 0.01 . Graphs and figures were drawn using Microsoft Excel 2017 and Adobe Photoshop CS6.

\section{Results}

Upland rice cv. IRAT109 showed a better germination rate and a better growth of radicle than lowland rice cv. Yuefu under both control conditions and PEG-induced drought stress (Fig. 1 Suppl.). The germination vigour, root length, and shoot length of IRAT109 were significantly higher than those of Yuefu (1.22-, 1.35-, and 1.26-times higher, respectively, under control conditions, and 3.29-, 1.70-, and 1.20-times higher, respectively, under drought stress; Fig. 1). Thus, upland rice was less susceptible to drought than lowland rice. Under PEG-induced stress, the $\mathrm{GA}_{3}$ content of IRAT109 was significantly higher than that of Yuefu, whereas in ABA content, no significant difference between IRAT109 and Yuefu were found (Fig. 2). The $\mathrm{GA}_{3}$ / ABA ratio of IRAT109 was significantly higher(1.15and 1.49-times) than that of Yuefu under control conditions and PEG-induced stress, respectively. $\alpha$-Amylase activity and soluble sugar content showed no difference between IRAT109 and Yuefu under control conditions. Under PEG stress, $\alpha$-amylase activity and soluble sugar content in IRAT109 were significantly higher (1.39- and 1.68-times) than in Yuefu (Fig. 3). Upland rice was more sensitive to $\mathrm{GA}_{3}$ application than lowland rice under PEG-induced stress (Fig. 1 Suppl.). The germination vigour, root length, shoot length, soluble sugar content, and $\alpha$-amylase activity of the IRAT109 significantly increased after $\mathrm{GA}_{3}$ treatment, but there was no significant increase in Yuefu (Figs. 1 and 2).

In order to identify the differentially expressed genes during seed germination between upland rice and lowland rice under drought stress, a genome-wide transcriptome analysis was performed by the Illumina Hiseq ${ }^{\mathrm{TM}} 2000$ platform. After sequencing, 23429106 and 20150182 reads were generated in Yuefu and IRAT109, respectively (Table 1). Almost 91.86 and $92.93 \%$ of reads were uniquely mapped to the reference genome in Yuefu and
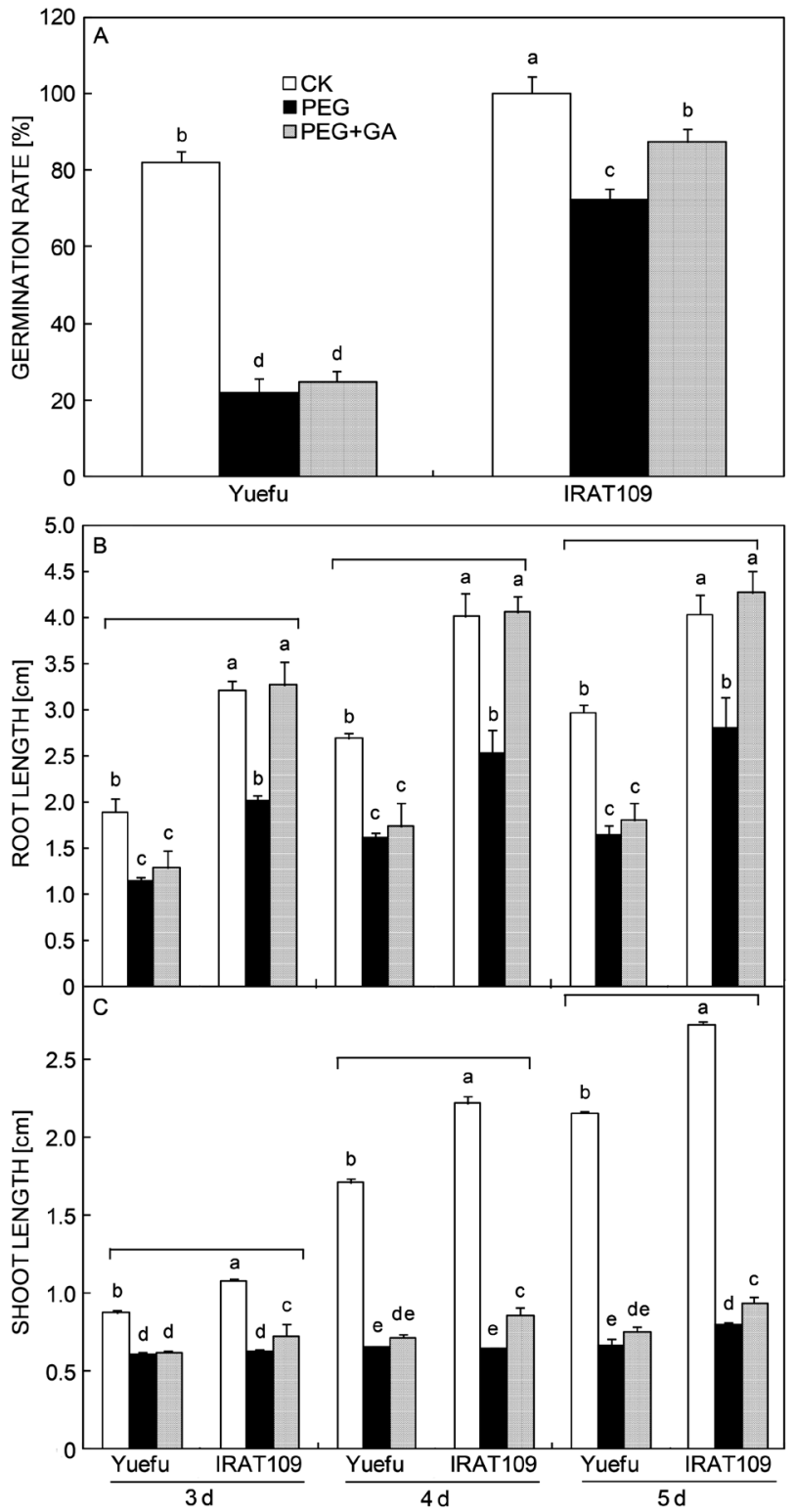

Fig. 1. Effect of $15 \%(\mathrm{~m} / \mathrm{v})$ polyethylene glycol (PEG) and PEG plus $0.1 \mu \mathrm{M}$ gibberellic acid (PEG+GA) on seed germination of upland rice cv. IRAT109 and lowland rice cv. Yuefu. $A$ Germination rate after 3 d. $B$ - Root length after 3, 4, and 5 d of treatment. $C$ - Shoot length after 3, 4, and $5 \mathrm{~d}$ of treatment. Means \pm SEs, $n=3$ sets of 100 seeds each.Ddifferent letters indicate significant differences at $P \leq 0.05$ analyzed and marked separately in each day. CK - control.

IRAT109, respectively. According to $G O$ database (http:// www.geneontology.org/), there were 31485 annotated genes. Comparing Yuefu and IRAT109, 2 171 DEGs were

Table 1. An RNA-seq data summary and read alignment statistics.

\begin{tabular}{lllll}
\hline Samples & Total Reads & Mapped reads & Paired-end mapped reads & Uniquely mapped reads \\
\hline Yuefu & 23429106 & $21373128(91.22 \%)$ & $19633942(91.86 \%)$ & $21058329(98.53 \%)$ \\
IRAT109 & 20150182 & $18480714(91.71 \%)$ & $17175046(92.93 \%)$ & $18200843(98.49 \%)$ \\
\hline
\end{tabular}




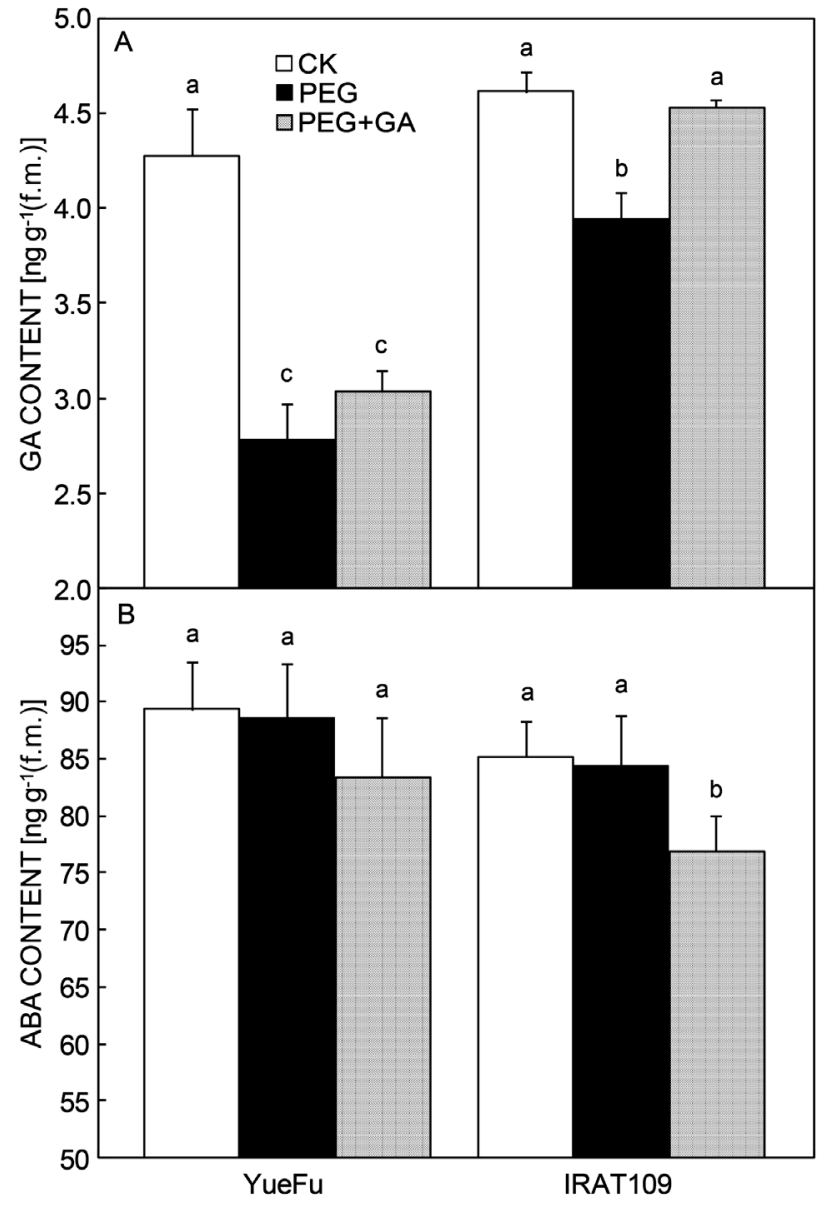

Fig. 2. Content of gibberellic acid $\left(\mathrm{GA}_{3}\right)(A)$ and abscisic acid (ABA) $(B)$ of seeds of rice cv. IRAT109 and cv. Yuefu after 1 $\mathrm{d}$ of germination in water $(\mathrm{CK})$, polyethylene glycol (PEG), or PEG $+\mathrm{GA}$. Means \pm SEs, $n=3$. Different letters indicate significant differences at $P \leq 0.05$.

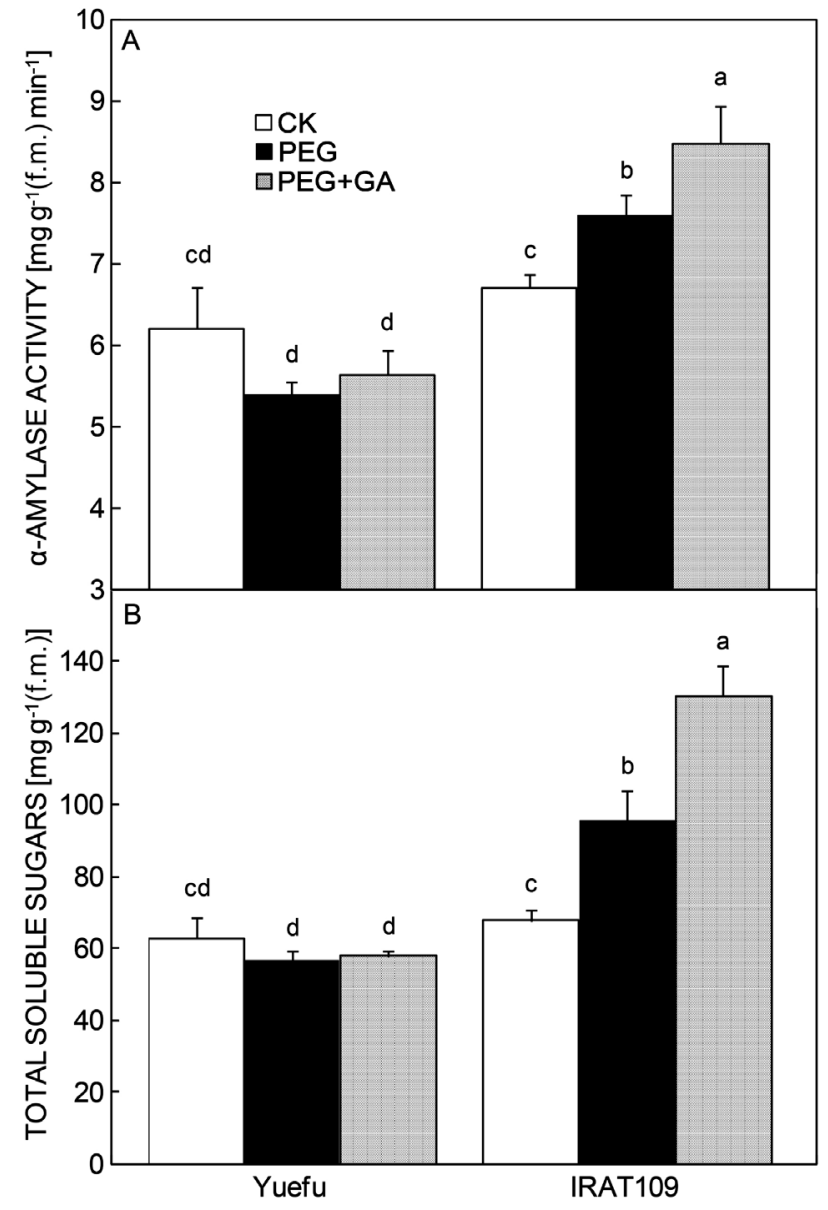

Fig. 3. Activity of $\alpha$-amylase $(A)$ and contetnt of total soluble sugars $(B)$ in seeds of rice cv. IRAT109 and cv. Yuefuafter $1 \mathrm{~d}$ of germination in water (CK), polyethylene glycol (PEG), or PEG + gibberellic acid (PEG + GA). Means \pm SEs, $n=3$. Different letters indicate significant differences at $P \leq 0.05$.

Table 2. Differentially expressed genes related to GAs, $\alpha$-amylase, and expansin under PEG for $1 \mathrm{~d}$. FDR - false discovery rate.

\begin{tabular}{lllll}
\hline Groups & G Gene ID & Gene name and description & $\begin{array}{l}\text { IRAT109 vs. Yuefu } \\
\text { fold change }\left(\log _{2}\right)\end{array}$ & FDR \\
\hline GA & Os01g0177400 & OsGA3ox2 & 1.8468 & $3.48 \mathrm{E}-05$ \\
& Os02g0567800 & gibberellin receptor GID1L2, putative & 1.3920 & $5.56 \mathrm{E}-03$ \\
& Os08g0475400 & gibberellin receptor GID1L2, putative & 1.4375 & $3.06 \mathrm{E}-03$ \\
& Os06g0214800 & gibberellin receptor GID1L2, putative & 1.6000 & $3.55 \mathrm{E}-04$ \\
& Os08g0547800 & gibberellin receptor GID1, putative & 2.3214 & $3.16 \mathrm{E}-05$ \\
\multirow{4}{*}{-amylase } & Os02g0765400 & a-amylase precursor & 2.1655 & $3.19 \mathrm{E}-08$ \\
& Os08g0473900 & OsAmy3D & 2.2161 & $2.26 \mathrm{E}-08$ \\
& Os09g0457600 & $\alpha$-amylase precursor & 2.7264 & $9.10 \mathrm{E}-13$ \\
& Os01g0357400 & $\alpha$-amylase1 B & 5.0555 & $0.00 \mathrm{E}+00$ \\
& Os02g0765600 & RAmy1A & 3.0579 & $3.33 \mathrm{E}-16$ \\
& Os01g0248900 & OsEXPA8 & 3.5811 & 0.0000166 \\
& Os05g0277000 & similar to OsEXPA3 & 3.7917 & $1.10 \mathrm{E}-10$ \\
& Os05g0276500 & OsEXPA3 & 4.5033 & $1.88 \mathrm{E}-12$ \\
& Os04g0228400 & OsEXPA1 & 4.6853 & $7.76 \mathrm{E}-14$ \\
\hline
\end{tabular}




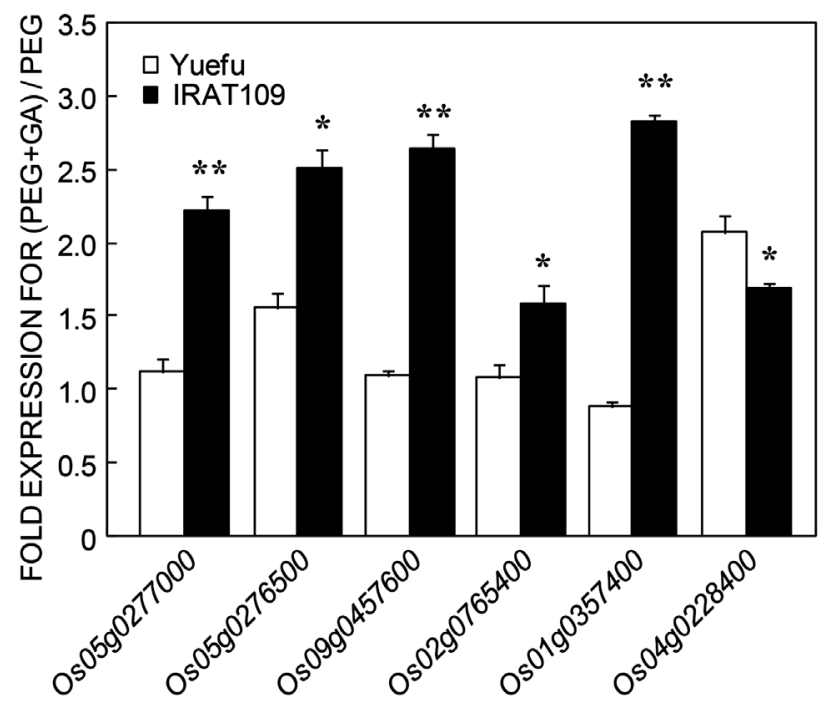

Fig. 4. Ratios of gene expressions of six $\alpha$-amylase and expansin related genes in rice cv. IRAT109 and cv. Yuefu under polyethylene glycol plus gibberellic acid (PEG+GA) and PEG treatments for $1 \mathrm{~d}$. Means \pm SEs, $n=3, *$ and $* *$ indicate significant differences at $P \leq 0.05$ and $P \leq 0.01$, respectively.

identified following the threshold $P<0.05$ and $\log _{2} \geq 1.00$, and were mapped to the $G O$ database. Approximately $63.61 \%$ of DEGs were upregulated in IRAT109. Real-time quantitative PCR was used to validate the expression of six randomly selected genes. Consistent expression trends between RNA sequencing and quantitative PCR were observed for all six genes, which indicates that the RNAseq data were credible (Fig. 2 Suppl.). To understand the functions of DEGs, all 2171 DEGs were categorized into 62 functional groups, and then categorized into 3 main functional groups (cellular component, molecular function, and biological process) according to $G O$ terms and $K E G G$ pathway analysis (Fig. 3 Suppl.). Of the 2171 DEGs, 5 GA related genes, $5 \alpha$-amylase related genes, and 4 expansin related genes were upregulated in IRAT109 compared to Yuefu. The five $\alpha$-amylase related genes and four expansin related genes had an average $\log _{2}$ of 3.04 and 4.14, respectively (Table 2). The five GA related genes included GA3-oxidase gene (OsGA3ox2) and four putative gibberellin receptor genes. The five $\alpha$-amylase related genes included two $\alpha$-amylase genes (OsAmy $3 D$ and RAmy1A), two putative $\alpha$-amylase precursor genes, and 1 putative a-amylase isozyme $C$ gene. These five expansin related genes included $3 \alpha$-expansin genes (OsEXPA8, OsEXPA3, and OsEXPA1), and one putative expansin precursor gene.

Real-time quantitative PCR results show that the expression of $\alpha$-amylase related genes and expansin related genes in germinating seeds under PEG stress were upregulated by $\mathrm{GA}_{3}$ treatment except for $0 s 01 g 0357400$ in Yuefu. The genes $O s 05 g 0277000$ (a putative expansin precursor), Os05g0276500 (OsEXPA3), Os09g0457600 (a putative $\alpha$-amylase precursor), Os02g0765400 (a putative $\alpha$-amylase precursor), and Os01g0357400 (a putative $\alpha$-amylase isozyme C) were induced in IRAT109 by $\mathrm{GA}_{3}$, and the gene expression ratio of $(\mathrm{PEG}+\mathrm{GA}) / \mathrm{PEG}$ for these five genes in IRAT109 were 1.98, 1.61, 2.41, 1.47, and 3.20 times higher than in Yuefu, respectively (Fig. 4). Only Os04g0228400(OsEXPA1) was significantly induced by GA in Yuefu.

\section{Discussion}

Insufficient water uptake during imbibition stage of seed germination is one of the main reasons for poor seedling establishment (Murillo-Amador et al. 2002). Upland rice with better drought tolerance was widely adopted in DSR (Gupta and O'Toole 1986). In this study, the germination vigour, root length, and shoot length significantly decreased in both the rice cultivars under PEG-induced drought stress, but the seed germination of IRAT109 was less affected than that of Yuefu. Higher $\mathrm{GA}_{3}$ content, $\alpha$-amylase activity, and soluble sugar content were observed in the germinating seeds of upland rice in comparison to lowland rice under PEG-induced stress. Also, upland rice was more sensitive to exogenous $\mathrm{GA}_{3}$ than lowland rice. The GAs and ABA are key plant hormones that regulate seed germination (Angelovici et al. 2010). The GAs play an important role in germination initiation and radicle protrusion, whereas ABA is involved in the whole process of seed germination. The high $\mathrm{GA}_{3}$ content and $\mathrm{GA}_{3} / \mathrm{ABA}$ ratio in upland rice promoted the synthesis of $\alpha$-amylase. So, more soluble sugars produced by higher $\alpha$-amylase activity could provide energy for seed germination in upland rice. Linkies and Leubner-Metzger (2012) thought that $\mathrm{GA}_{3}$ also promotes the synthesis of cell wall remodeling proteins, which regulates embryo growth and endosperm weakening during seed germination. Therefore, high $\mathrm{GA}_{3}$ content which promotes the synthesis of $\alpha$-amylase and cell wall proteins, may be the main reason for rather high seed germination in upland rice under drought stress.

Transcriptome analysis has provided a new insight into the mechanisms of seed germination in Gossypium australe, Arabidopsis, and wheat (Dekkers et al. 2013, Tao et al. 2013, Yu et al. 2014). In this study, RNA-seq analysis was used to characterize the differences between transcriptomes of germinating seeds of upland and lowland rice under PEG-induced stress. There were 2171 DEGs between IRAT109 and Yuefu belonging to 62 functional groups. Among these, 14 genes related to GA, $\alpha$-amylase, and expansin showed significantly higher expressions in IRAT109 than in Yuefu. The GA related genes including OsGA3ox2 and four putative gibberellin receptor genes were more expressed in IRAT109 than in Yuefu. The OsGA3ox 2 encodes $3 \beta$-hydroxylase which catalyzes the final step of the $\mathrm{GA}_{3}$ biosynthetic pathway and produces bioactive $\mathrm{GA}_{3}$ (Itoh et al. 2001). The function of $\mathrm{GA}_{3}$ receptor is to perceive the signal of $\mathrm{GA}_{3}$ and thus stimulate growth. During seed germination, $\alpha$-amylase catalyzes the first step in starch breakdown, which contributes to the supply of carbon. In this study, two $\alpha$-amylase genes (OsAmy $3 D$ and $R A m y 1 A$ ), two putative $\alpha$-amylase precursor genes, and one putative $\alpha$-amylase isozyme $\mathrm{C}$ gene were highly 
expressed in IRAT109. The OsAmy3D is the first expressed $\alpha$-amylase gene during rice seedling development, and it plays an important role in sugar production during the early stage of seed germination (Hwang et al. 1998). The expression of RAmylA, which is most abundant in the germinating seed and related to seeding vigour, may be the rate-limiting factor in controling rice seedling vigour (Huang et al. 1993, Karrer et al. 1993). Expression of $\alpha$-amylase gene is induced by GA (Finkelstein and Gibson 2002). Expansin is well known for its cell wall loosening activity and is involved in cell expansion and development. Expansin genes, OsEXPA8, OsEXPA3, and OsEXPA1, and one putative $\alpha$-expansin precursor gene showed higher expressions in IRAT109 than in Yuefu. The OsEXPA8 is a root-specific gene that has been proven to improve root system architecture and enhance plant height by facilitating cell extension (Ma et al. 2013, Wang et al. 2014). The OsEXPA3 promotes root growth by mediating cell wall loosening and is necessary for root system development in rice (Qiu et al. 2014). The OsEXPA1 controls coleoptile and internode development in seed germination (Cho and Kende 1997, Huang et al. 2000). The higher expression of genes related to GA, $\alpha$-amylase, and expansin in IRAT109 than in Yuefu may have assisted seed germination and radicle development by inducing synthesis of hydrolytic enzymes, mobilizing seed storage reserve, and stimulating cell expansion. In addition, majority of $\alpha$-amylase related genes and expansin related genes were induced in upland rice by $\mathrm{GA}_{3}$ treatment. The results indicate that $\mathrm{GA}$ and its downstream regulatory genes play important roles in promoting seed germination in upland rice under drought stress.

\section{References}

Anders, S., Huber, W.: Differential expression analysis for sequence count data. - Genome Biol. 11: R106, 2010.

Angelovici, R., Galili, G., Fernie, A.R., Fait, A.: Seed desiccation: a bridge between maturation and germination. - Trends Plant Sci. 15: 211-218, 2010.

Basra, S.M.A., Farooq, M., Tabassum, R., Ahmed, N.: Physiological and biochemical aspects of seed vigor enhancement treatments in fine rice (Oryza sativa L.). - Seed Sci. Technol. 33: 623-628, 2005.

Bernfeld, P.: Amylases $\alpha$ and $\beta$. - Methods Enzymol. 1: 149-158, 1955.

Bewley, J.D.: Seed germination and dormancy. - Plant Cell 9: 1055-1066, 1997.

Cho, H.T., Kende, H.: Expression of expansin genes is correlated with growth in deepwater rice. - Plant Cell. 9: 1661-1671, 1997.

Dekkers, B.J.W., Pearce, S., Van Bolderen-Veldkamp, R.P., Marshall, A., Widera, P., Gilbert, J., Drost, H., Bassel, G.W., Müller, K., King, J.R., Wood, A.T.A., Grosse, I., Quint, M., Krasnogor, N., Leubner-Metzger, G., Holdsworth, M.J., Bentsink, L.: Transcriptional dynamics of two seed compartments with opposing roles in Arabidopsis seed germination. - Plant Physiol. 163: 205-215, 2013.

Dubois, M., Giles, K.A., Hamilton, J.K., Roberes, P.A., Smith, F.: Colorometric method for determination of sugars and related substances. - Ann. Chem. 28: 350-356, 1956.

Farooq, M., Barsa, S., Wahid, A.: Priming of field-sown rice seed enhances germination, seedling establishment, allometry and yield. - Plant Growth Regul. 49: 285-294, 2006.

Finkelstein, R.R., Gibson, S.I.: ABA and sugar interactions regulating development: cross-talk or voices in a crowd? Curr. Opin. Plant Biol. 5: 26-32, 2002.

Gupta, P. C., O'Toole, J.C.: Upland Rice: A Global Perspective. - Int. Rice Res. Inst., Manila 1986.

Hu, H.H., Xiong, L.Z.: Genetic engineering and breeding of drought-resistant crops. - Annu. Rev. Plant Biol. 65: 715-741, 2014.

Huang, J., Takano, T., Akita, S.: Expression of $\alpha$-expansin genes in young seedlings of rice (Oryza sativa L.). - Planta 211: 467$473,2000$.

Huang, N., Chandler, J., Thomas, B.R., Koizumi, N., Rodriguez, R.L.: Metabolic regulation of $\alpha$-amylase gene expression in transgenic cell cultures of rice (Oryza sativa L.). - Plant mol. Biol. 23: 737-747, 1993.

Hwang, Y.S., Karrer, E.E., Thomas, B.R., Chen, L., Rodriguez, R.L.: Three $c i s$-elements required for rice $\alpha$-amylase $A m y 3 D$ expression during sugar starvation. - Plant mol. Biol. 36: 331$341,1998$.

Itoh, H., Ueguchi-Tanaka, M., Sentoku, N., Kitano, H., Matsuoka, M., Kobayashi, M.: Cloning and functional analysis of two gibberellin 3 $\beta$-hydroxylase genes that are differently expressed during the growth of rice. - Proc. nat. Acad. Sci. USA 98: 8909-8914, 2001.

Karrer, E.E., Chandler, J.M., Foolad, M.R., Rodriguez, R.L.: Seedling vigor is correlated to the expression of one member of the rice $\alpha$-amylase multigene family. - Euphytica. 66: 163169,1993

Lee, H.S., Sasaki, K., Kang, J.W., Sato, T., Song, W.Y., Ahn, S.N.: Mesocotyl elongation is essential for seedling emergence under deep-seeding condition in rice. - Rice 10: 32, 2017.

Lee, S.S., Kim, J.H.: Total sugars, $\alpha$-amylase activity and germination after priming of normal and aged rice seeds. Korean J. Crop Sci. 45: 108-111, 2000.

Linkies, A., Leubner-Metzger, G.: Beyond gibberellins and abscisic acid: how ethylene and jasmonates control seed germination. - Plant Cell Rep. 31: 253-270, 2012.

Liu, H.Y., Hussain, S., Zheng, M.M., Sun, L.M., Shad, F., Huang, J.L., Cui, K.H., Nie, L.X.: Progress and constraints of dry direct-seeded rice in China. - J. Food Agr. Environ. 12: 465$472,2014$.

Liu, L., Xia, W.L., Li, H.X., Zeng, H.L., Wei, B.H., Han, S.Y., Yin, C.X.: Salinity inhibits rice seed germination by reducing $\alpha$-amylase activity via decreased bioactive gibberellin content. - Front Plant Sci. 9: 275, 2018

Ma, N.N., Wang, Y., Qiu, S.C., Kang, Z.H., Che, S.G., Wang, G.X., Huang, J.L.: Overexpression of OSEXPA8, a rootspecific gene, improves rice growth and root system architecture by facilitating cell extension. - PLOS ONE. 8: e75997, 2013.

Mahender, A., Anandan, A., Pradhan, S.K.: Early seedling vigour, an imperative trait for direct-seeded rice: an overview on physio-morphological parameters and molecular markers. - Planta 241: 1027-1050, 2015.

Miransari, M., Smith, D.L.: Plant hormones and seed germination. - Environ. exp. Bot. 99: 110-121, 2014.

Murillo-Amador, B., Lopez-Aguilar, R., Kaya, C., LarrinagaMayoral, J., Flores-Hernandez, A.: Comparative effects of $\mathrm{NaCl}$ and polyethylene glycol on germination, emergence and seedling growth of cowpea. - J. Agron. Crop Sci. 188: 235247, 2002.

Qiu, S.C., Ma, N.N., Che, S.G., Wang, Y., Peng, X.Y., Zhang, G.P., Wang, G.X., Huang, J.L.: Repression of OsEXPA3 expression leads to root system growth suppression in rice. - 
Crop Sci. 54: 2201-2213, 2014.

Rajjou, L., Duval, M., Gallardo, K., Catusse, J., Bally, J., Job, C., Job, D.: Seed germination and vigor. - Annu. Rev. Plant Biol. 63:507-533, 2012.

Shu, K., Liu, X.D., Xie, Q., He, Z.H.: Two faces of one seed: hormonal regulation of dormancy and germination. - Mol. Plants 9: 34-45, 2016.

Tao, T., Zhao, L., Lv, Y.D., Chen, J.D., Hu, Y., Zhang, T.Z., Zhou, B.L.: Transcriptome sequencing and differential gene expression analysis of delayed gland morphogenesis in Gossypium australe during seed germination. - PLOS ONE 8: e75323, 2013

Trapnell, C., Williams, B.A., Pertea, G., Mortazavi, A., Kwan, G., Van Baren, M.J., Salzberg, S.L., Wold, B.J., Pachter, L.: Transcript assembly and quantification by RNA-seq reveals unannotated transcripts and isoform switching during cell differentiation. - Nat. Biotechnol. 28: 511-515, 2010.
Wang, Y., Ma, N.N., Qiu, S.C., Zou, H.Y., Zang, G.C., Kang, Z.H., Huang, J.L.: Regulation of the $\alpha$-expansin gene OsEXPA8 expression affects root system architecture in transgenic rice plants. - Mol. Breed. 34: 47-57, 2014.

Yang, J.C., Zhang, J.H., Wang, Z.Q., Zhu, Q.S., Wang, W.: Hormonal changes in the grains of rice subjected to water stress during grain filling. - Plant Physiol. 127: 315-323, 2001.

Yu, Y.L., Guo, G.F., Lv, D.W., Hu, Y.K., Li, J.R., Li, X.H., Yan, Y.M.: Transcriptome analysis during seed germination of elite Chinese bread wheat cultivar Jimai 20. - BMC Plant Biol. 14: 1-19, 2014.

Zhao, H.Y., Zhang, H.M., Cui, P., Ding, F., Wang, G.C., Li, R.J., Jenks, M.A., Lu, S.Y., Xiong, L.M.: The putative E3 ubiquitin ligase ECERIFERUM9 regulates abscisic acid biosynthesis and response during seed germination and postgermination growth in Arabidopsis. - Plant Physiol. 165: 1255-1268, 2014. 